\title{
Lyell's syndrome: a true medical emergency
}

\author{
Salmi A*, Ameur A, Slimani M and Messaif D \\ Department of Medical and Surgical emergencies, University Hospital center Mustapha, Algiers, Algeria
}

\begin{abstract}
Lyell's syndrome or toxic epidermal necrolysis is a bullous dermatosis, of étiologie aetiology, very often drug. It is an acute necrosis of the epidermis, with a clinical appearance of extensive burns. At this table are associated mucosal damage and, frequently, a multiorgan making poor prognosis. We report in this paper a case of toxic epidermal necrolysis, which illustrates the importance of early treatment in an intensive care unit, whose foundations are based on fluid and electrolyte intake, infection prevention and its treatment with appropriate antibiotics.
\end{abstract}

\section{Introduction}

In 1956 Lyell described the toxic epidermal necrolysis (TEN) about four patients with skin peeling similar to that observed in the burned, evoking epidermal necrolysis toxic origin without assimilating the polymorphe [1]. Erythema subsequently, it was noted that the same causes could induce both the Stevens-Johnson syndrome (SJS) and TEN and SJS an initial table could grow in TEN.

So, SJS and TEN are a very serious illness even variants: toxic epidermal necrolysis (TEN) substantially drug-induced differing only by the extent of cutaneous detachment $(<10$ per 100 of the total area for SJS. more than 30 p. 100 for TEN. Between $10-30 \%$ for the transitions the two forms).

This is a rare but serious drug eruption, unpredictable occurrence, leads to a destruction of the surface layer of the skin and mucous membranes $[2,3]$.

Many drugs that may be responsible: Allopurinol, sulfonamides, antiepileptic (carbamazepine, phenytoin, phenobarbital), Nonsteroidal anti-inflammatory derived of the oxicam ...) [4,5].

The therapeutic management is essentially symptomatic. It resembles that of severe burned through the stop of the suspect medication, fluid and electrolyte intake of quality and prevention and appropriate treatment of the infection. The objective of this work is to describe the epidemiology, etiology, clinical, therapeutic and evolutionary SL illustrated by the case of a patient hospitalized in intensive care for SL.

The prognosis is severe, evaluated using a specific scale of severity of the disease, the SCORTEN [6] and nearly $50 \%$ of sequelae, particularly eye, in survivors.

\section{Case presentation}

34-year-old woman without surgical or individual medical history admitted in intensive care unit to skin lesions and diffuse erythematous mouth.

The symptoms began 4 days after taking an antibiotic cephalexin like 1000, 3times 1 tablet per day (beta-lactamines antibiotic of the first-generation cephalosporin), marked by the installation of diffuse erythematous skin lesions, difficulty in breathing and a dry cough.
On admission clinical examination found a conscious patient stable hemodynamically, febrile at $39^{\circ} \mathrm{C}$.

The skin examination betrayed macular lesions and erythematous maculopapular, of varying sizes, sitting on the face, back and lower limbs which extended to the soles. The evaluation of the affected skin surface was more than $90 \%$, with a SCORTEN in 2.

The review found mucosal erosions of the oral mucosa and tongue ulceration, making any power not by oral route (Figures 1 and 2).

The standard blood test was without defects, even for téléthorax was normal.

The treatment, after stopping the offending drug (cefalexine), contained abundant electrolyte resuscitation to prevent functional renal failure, early parenteral nutrition and enteral, oral care with methylene blue and thromboembolic prophylaxis.

Regarding skin lesions, no specific treatment has been proposed, and was spontaneously favorable evolution after 10 days (Figures 3-5).

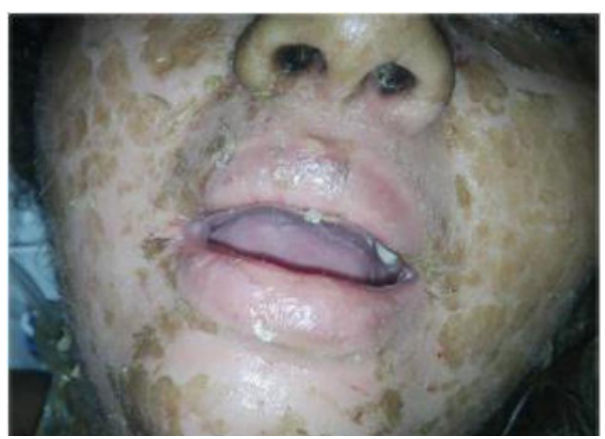

Figure 1. Erosions of the oral mucosa

Correspondence to: Amine Salmi, Department of Medical and Surgical Emergencies, University Hospital center Mustapha, Algiers, Algeria, Tel: 0663503399; E-mail: salmi_amine@yahoo.fr

Key words: toxic epidermal necrolysis, emergency treatment, prognosis

Received: November 22, 2016; Accepted: December 16, 2016; Published: December 19, 2016 


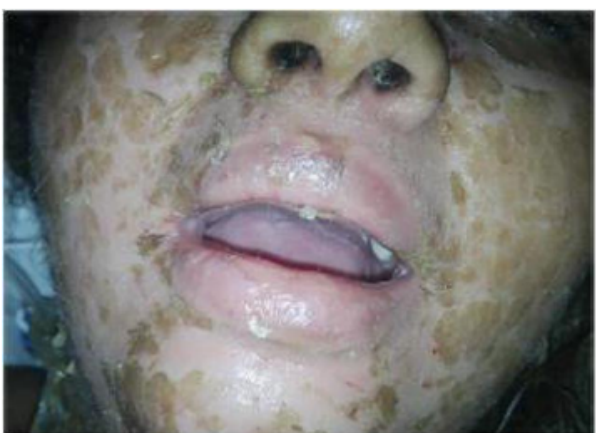

Figure 2. Bullous lesions (right forearm).

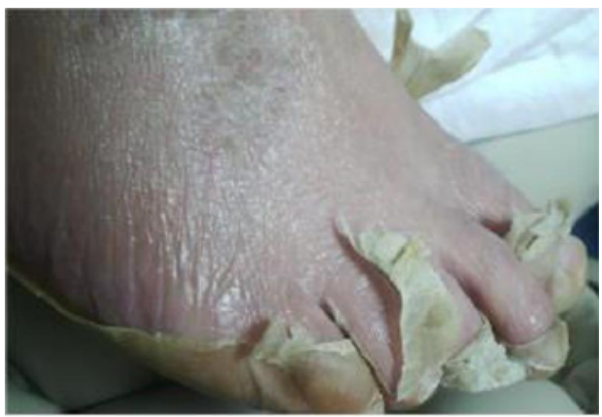

Figure 3. Epithelial regeneration and hyperpigmentation (Left foot)

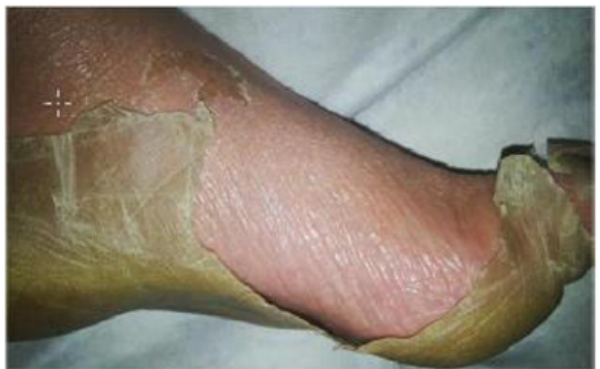

Figure 4. Epithelial regeneration and hyperpigmentation (Right foot).

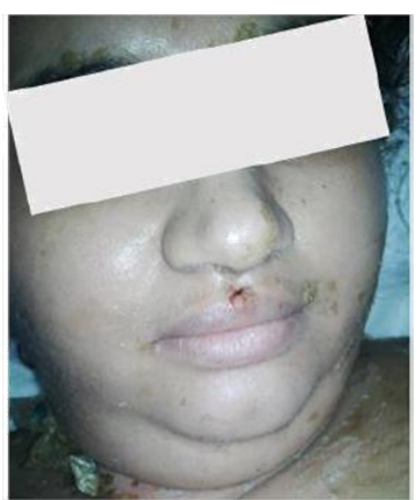

Figure 5. Healing lesions of the face.

\section{Discussion}

Lyell's syndrome is a rare clinical entity. Its impact on the model series is 1 to 2 cases per million year [7].

This is a serious drug allergy, exceptional and unpredictable. It leads to destruction more or less extensive in the most superficial party of the skin. The mucous membranes of the mouth, eyes and genitalia are also affected.The disease extends for a few days (five on average). The severity depends largely on the final extent of the lesions of the skin and mucous membranes. The regeneration of the skin is fast, averaging 10 to 15 days (Figures 3-5).

Clinically $[7,8]$ topography skin lesions predominate in the face, neck and trunk, spreading rapidly to all integument; the sudden onset of large epidermal detachment gave way to a red oozing dermis, which was the case in our patient. The evolution of the cutaneous symptoms was spectacular. Skin lesions remained without superinfection clean and complete healing was done after 10 days compared to the beginning of installation.

The responsibility for drugs in the genesis of this syndrome is estimated at $60-70 \%$ of cases. The onset time is 1 to 4 weeks after the beginning of the drug taken, on average 12-14 days. The accident may begin several days after stopping the drug if its elimination half-life is long. When the treatment is taken for more than 2 months, the risk becomes negligible. Its occurrence is independent of the dose and minor exposure can be enough to trigger the maladie $[9,10]$.

According to data from the literature, almost all antibiotics can be criminalized, with a particular frequency for penicillins $[9,11]$, quinolones succeed then [12,13] vancomycin [14], macrolides and antituberculous drugs $[9,15]$.

In our patient, the concept of drug intake was found: she received three drugs: A cough suppressant (ZEAL), a nutritional supplement (GESTARELLE G Pregnancy) and betalactamines antibiotic. Cephalexin 1000 (antibiotic of first generation cephalosporin).

Of the three drugs used by the patient, they are beta-lactamines antibiotics that are strongly suspected in the onset of this case NET: the patient was already under GESTARELLE G Pregnancy, several weeks ago one hand (over 1 month) and secondly the antitussive was prescribed after the onset of skin lesions, for a dry cough. Treatment of SL is symptomatic that the first step is stopping all suspect drug. At the same time with this decision, the management is based on fluid and electrolyte intake and quality of analgesia in an aseptic environment rigorous.

Parenteral nutrition is often seen indicated the presence of lesions year the oral cavity, making any oral feeding difficult or impossible. In this case, power is hyperproteic seen hypercatabolism which characterizes this situation.

Finally, local mucocutaneous care, made in strict aseptic technique is another supportive measure until wound healing. There is currently no specific treatment to be well established. Systemic corticosteroids remains controversial, various immunosuppressive treatments (Cyclophosphamide, cyclosporine) have been tried in some cases without compelling evidence of their effectiveness. The benefits of high doses of intravenous immunoglobulins have not been confirmed. SL prognosis remains reserved, depends on several pejorative factors including age, the surface of the skin peeling, the delay in diagnosis and management, late discontinuation of the drug and especially infectious complications, frequent and formidable as responsible for a high mortality rate. It is evaluated using a specific scale of severity of the disease, the SCORTEN [16]. It consists of seven clinical and laboratory parameters that must be collected within 24 hours after admission (Table 1).

The most significant effects are scars dyschromic type of hyperpigmentation (Figures 3 and 4), and corneal sequelae (pillowcases, 
Table 1. Severity of illness Score for Toxic Epidermal Necrolysis (SCORTEN).

\begin{tabular}{|c|c|c|c|c|}
\hline \multicolumn{5}{|c|}{ SCORTEN and predicted mortality } \\
\hline \multicolumn{4}{|c|}{ SCORTEN (0à7) } & Mortality \\
\hline Parameters & 0 & 1 & Score & Mortality \% \\
\hline Age & $<40$ years & $>40$ years & $0-1$ & 3.2 \\
\hline Carrying diagnosis of cancer & Non & Oui & 2 & 12.1 \\
\hline Heart rate & $\begin{array}{c}<120 \\
\text { beats/minute }\end{array}$ & $\begin{array}{c}>120 \\
\text { beats/minute }\end{array}$ & 3 & 35.3 \\
\hline Detached Surface & $<10 \%$ & $>10 \%$ & 4 & 58.3 \\
\hline $\begin{array}{l}\text { Blood Urea } \\
\text { Nitrogen(mmol/l) }\end{array}$ & $<10$ & $>10$ & $>5$ & $>90$ \\
\hline Bicarbonate $(\mathrm{mmol} / \mathrm{L})$ & $>20$ & $<20$ & \multirow{2}{*}{\multicolumn{2}{|c|}{ ||IIIIIIIIIIIIIIIIIIIIIIIIIIIIIIIIIIII }} \\
\hline Blood glucose (mmol/1) & $<14$ & $>14$ & & \\
\hline
\end{tabular}

white spots, which may require a corneal transplant).

A score lower or equal to 2 indicates a probability of survival about $90 \%$, and when it is upper or equal to 4 the probability of survival is lower than $50 \%$.

\section{Conclusion}

Lyell's syndrome is a pathology rare but grave, burdened with high morbidity and mortality. This observation illustrates the importance of early management of patients with NET in an intensive care unit. Finally, it is important to inform the patient about the need for early consultation before any post-medicated dermatological symptoms. These prevention methods will further reduce the incidence of this disease and improve prognosis by early treatment.

\section{Conflicts of interest}

On behalf of all authors, the corresponding author states that there is no conflict of interest.

\section{References}

1. Lyell A (1956) Toxic epidermal necrolysis: an eruption resembling scalding of the skin. Br J Dermatol 68: 355-361.[Crossref]

2. Roujeau JC, Guillaume JC, Fabre JP, Penso D, Fléchet ML, et al. (1990) Toxic epidermal necrolysis (Lyell syndrome). Incidence and drug etiology in France, 19811985. Arch Dermatol 126: 37-42.[Crossref]

3. Chan HL (1995) Toxic epidermal necrolysis in Singapore, 1989 through 1993: incidence and antecedent drug exposure. Arch Dermatol 131: 1212-1213.[Crossref]

4. Lissia M, Mulas P, Bulla A, Rubino C (2010) Toxic epidermal necrolysis (Lyell's disease). Burns 36: 152-163.[Crossref]
5. Fritsch PO, Sidoroff A (2000) Drug-induced Stevens-Johnson syndrome/toxic epidermal necrolysis. Am J Clin Dermatol 1: 349-360.[Crossref]

6. Bastuji-Garin S, Fouchard N, Bertocchi M, Roujeau JC, Revuz J, et al. (2000) SCORTEN: a severity-of-illness score for toxic epidermal necrolysis. J Invest Dermatol 115: 149-153.[Crossref]

7. Chosidow O, Roujeau JC, Revuz J (1991) Syndrome de Lyell (nécroseépidermiquetoxique). EMC 12450 A 10.

8. Couadau E, Carles M, Ichai C (2001) Troubles cutanés en réanimation. Conférenced'actualisation, 551-70. SociétéFrançaiseAnesthésieRéanimation, Elsevier, Paris.

9. Wolkenstein PE, Roujeau JC, Revuz J (1998) Drug induced toxic epidermal necrolysis Clin Dermatol 16: 399-409.

10. Correia O, Chosidow O, Saiag P, Bastuji-Garin S, Revuz J, et al. (1993) Evolving pattern of drug-induced toxic epidermal necrolysis. Dermatology 186: 32-37.[Crossref]

11. Correia O, Chosidow O, Saiag P, Bastuji-Garin S, Revuz J, et al. (1993) Evolving pattern of drug-induced toxic epidermal necrolysis. Dermatology 186: 32-37.[Crossref]

12. Surbled M, Lejus C, Milpied B, Pannier M, Souron R (1996) [Lyell syndrome after amoxicillin administration in a 2 year old child]. Ann Fr AnesthReanim 15: 1095-1098. [Crossref]

13. Melde SL (2001) Ofloxacin: a probable cause of toxic epidermal necrolysis. Ann Pharmacother 35: 1388-1390.[Crossref]

14. Mandal B, Steward M, Singh S, Jones H (2004) Ciprofloxacin-induced toxic epiderma necrolysis (TEN) in a nonagerian: a case report. Age Ageing 33: 405-406.[Crossref]

15. Prey S, Sparsa A, Boumediene A, Bonnetblanc JM, Weinbreck P, et al. (2007) [Cutaneous drug reactions induced by glycopeptides]. Med Mal Infect 37: 270-274. [Crossref]

16. MameThierno D, On S, ThiernoNdiaye S, Ndiaye B (2001) [Lyell syndrome in Senegal: responsibility of thiacetazone]. Ann Dermatol Venereol 128: 1305-1307.[Crossref]

Copyright: (C2016 Salmi A. This is an open-access article distributed under the terms of the Creative Commons Attribution License, which permits unrestricted use, distribution, and reproduction in any medium, provided the original author and source are credited. 